\title{
sciendo \\ CHALLENGES FACED BY BUSINESSES IN THE MINING INDUSTRY IN THE CONTEXT OF THE INDUSTRY 4.0 PHILOSOPHY
}

doi:10.2478/mape-2018-0078

Date of submission of the article to the Editor: 05/2018

Date of acceptance of the article by the Editor: 07/2018
MAPE 2018, volume 1, issue 1, pp. 621-626

Marta Sukiennik, PhD., Eng.

AGH University of Science and Technology, Poland

\begin{abstract}
This article presents the challenges that mining companies have in the face of the Industry 4.0 philosophy. Transformation of mining businesses into Industry 4.0 appears unavoidable. Due to the specific nature of the sector, the transformation will not be an easy one. This paper discusses the obstacles and challenges related to the transformation of businesses in the mining industry into the Industry 4.0. The history of industrial revolutions was presented, also as the idea of Industry 4.0 with its basic components. The concept of Industry 4.0 is also outlined and the studies which indicate the key issues in the transformation process are also cited. Based on these studies, it can be seen that the vast majority are issues in the field of production engineering and properly educated and qualified staff. Four main areas in which transformation into Industry 4.0 should be taking place are identified. Particular emphasis is placed on the area of technology and organizational culture. The mutual relations of management functions and ICT technologies have also been presented, which is one of the elements of the idea of Industry 4.0. Finally, the potential benefits for the organizational culture of the business of implementing the Industry 4.0 concepts are discussed.
\end{abstract}

Keywords: Industry 4.0, mining company, ICT, organizational culture

\section{INTRODUCTION}

Industry 4.0 is a concept which piques the interest of producers around the globe. This has been caused by the idea that, in view of the constantly changing and developing technology, there can be no future for production without implementing the premises of Industry 4.0 in order to stay in the game, businesses must consider making changes which will bring their processes closer and reorient their activity to that concept. The key terms that the businesses must embrace now are: additive manufacturing technologies, extended reality, analytical systems, virtual simulations, digital production management and industrial robotics. This in turn requires innovation, defined as a set of activities leading to the creation and then first practical implementation of new technical, process or organizational solutions (Pomykalski, 2001; Qinglin et al., 2018; Wan et al., 2014; Li et al., 2017). Therefore, innovations should be the main driver of all organizations, embedded in their management systems and organizational culture.

The organizational culture of a company is the factor which directly participates in and interacts with all processes within the company. The participation might be both positive and negative. The organizational culture can support processes, but also compromise them (Bąk et.al. 2016).

What are the key premises, guidelines and challenges for the organizational culture of a company in terms of the Industry 4.0 idea? The aim of the article is to show that the implementation of the 4.0 industry assumptions for Polish enterprises in the mining industry can bring a benefits for the company, but also for its organizational culture. 


\section{THE BASIC PREMISES OF INDUSTRY 4.0}

The term "Industry 4.0" is used interchangeably with the notion of the fourth industrial revolution. Its main premises are related to mutual use of automatization, processing and exchange of data and production technology.

Historically, the industry has undergone three major shifts in its approach to production. Those were:

- Industry 1.0, which was driven by mechanization and began with the invention and implementation of the steam engine (the Industrial Age);

- Industry 2.0, which was driven by electricity that eliminated the steam engine and opened the door for mass production;

- Industry 3.0, which was driven by digitization and began by the implementation of computers and software.

- Industry 4.0, which is driven by networking, i.e. the integration of systems and the creation of a net.

The aim of Industry 4.0 is to integrate both human workers and employees, and digitally controlled machinery, with the Internet and IT technologies. It is also based on identification, understood as a process (Fig. 1) in which materials produced or used for production can always be identified, and are able to communicate with each other. The communication may be both vertical and horizontal.

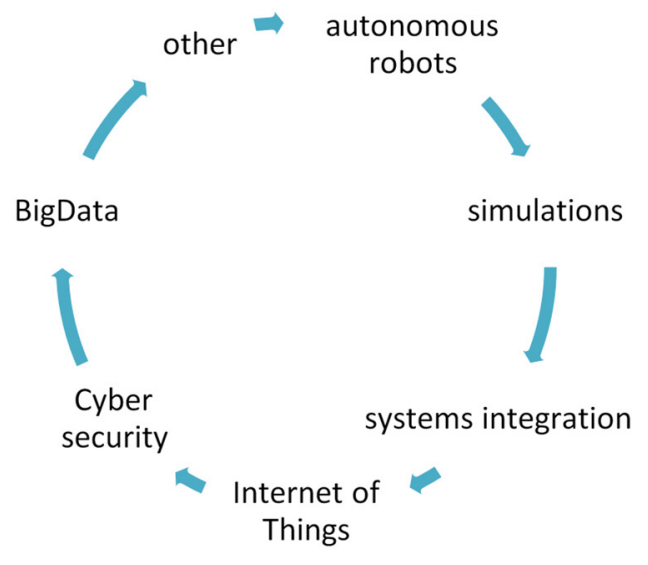

Fig. 1. Key components of Industry 4.0.

Source: own work on the basis of (www.automatykab2b.pl).

\section{THE MINING INDUSTRY IN TERMS OF THE INDUSTRY 4.0 IDEA - CHALLENGES AND}

\section{OBSTACLES}

Transformation of a company into the Industry 4.0 framework is neither simple nor obvious, and businesses face a number of challenges in this context. The survey conducted by (Control Engineering Polska and Inżynieria \& Utrzymanie Ruchu) shows that the greatest obstacles for the implementation of Industry 4.0 include (Fig. 2): 


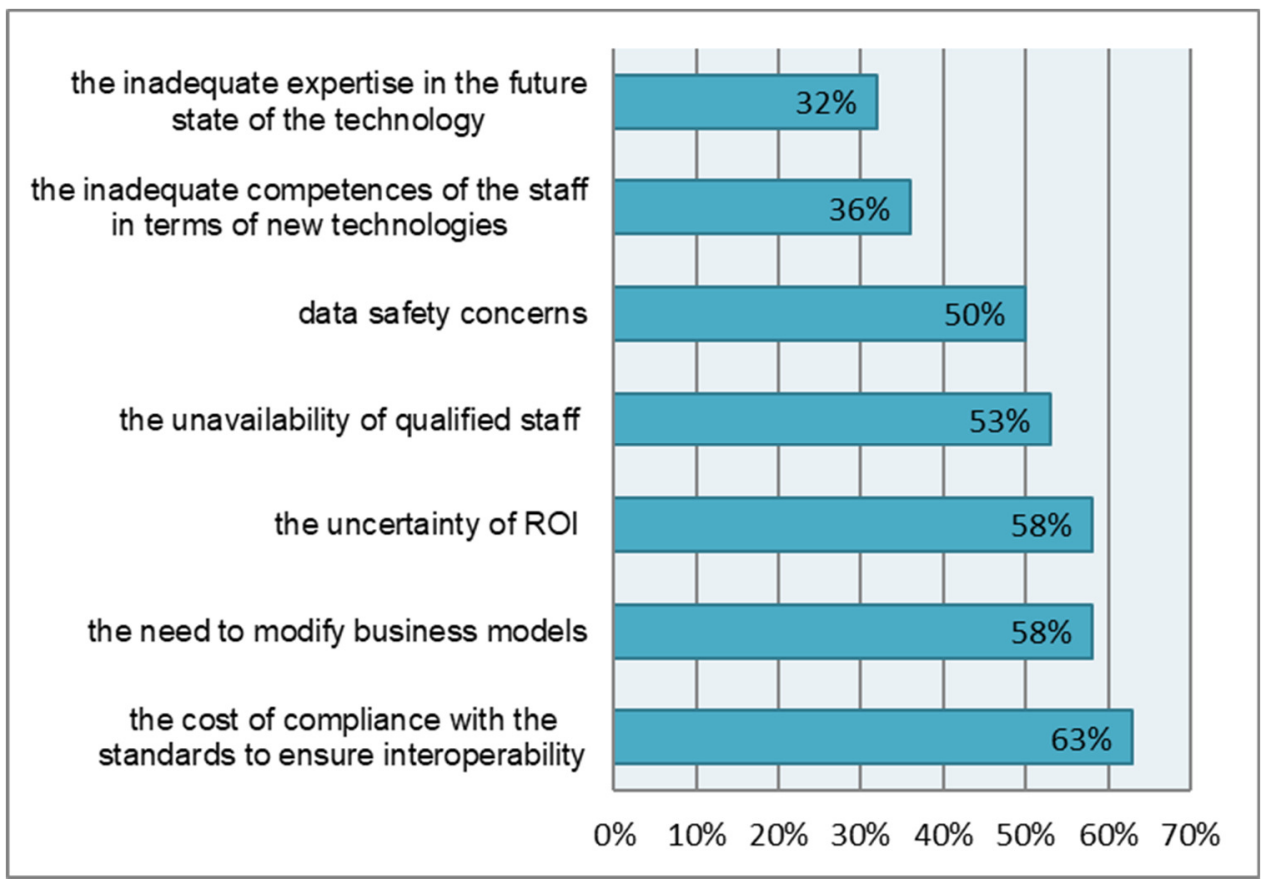

Fig. 2. Obstacles for the implementation of Industry 4.0 solutions

Source: own work based on the studies conducted by (Control Engineering Polska and Inżynieria \& Utrzymanie Ruchu)

Analyzing the obstacles listed above, it becomes clear that the majority of issues relate to production engineering. However, half of the respondents also indicated the unavailability of qualified staff as a major obstacle for implementing the Industry 4.0 philosophy. There are not enough data analysis specialists on the market. Furthermore, new technologies are a realm populated mainly by younger people and the demographic trends are not favorable in terms of supplying new specialists to the market. Possible solutions include training the existing staff in new technologies to increase their competences; however, this requires significant expenditures on the part of the company, both in terms of time and funding.

Data safety is a global issue, but given that Industry 4.0 additionally requires that all process elements communicate with each other in a network, the issues related to data safety and the protection of industrial and production systems particularly gain in importance.

Analyzing the premises of Industry 4.0, it becomes clear that any business that decides to accept the challenge and implement its concepts, will permanently change its model of operation. What does this transformation entail? Currently, the production process in industrial companies is related mainly to production engineering. This is the area that will undergo a major shift. According to the philosophy of Industry 4.0, the notion of Big Data will become commonplace. It will become necessary to analyze massive data volumes; data will be collected by virtually any machine and device; all technological processes will have to be constantly monitored; not only technical, but also quality parameters will have to be recorded - all this will on the one hand require continuous analysis, but on the other, it will lead to more efficient and economical production management.

But it is not only the technology that will undergo transformation - also the role of the employee will change. The new ICT solutions (among them the Machine-to-Machine [M2M] communications and Industrial Internet of Things [IIoT]) will also include the advanced information processing methods which will change the perspective on both the organization and the processes. Consequently, the role of the employee will change accordingly. The employee will have to master new skills related to new technologies, as well as competences to "delegate" responsibilities to the machines. This will be difficult mainly due to the need to recruit new, qualified staff. 
In the case of the mining industry, the transformation process may be particularly difficult. Both the specific nature of mining operations and the current situation in the industry contribute to a number of obstacles and challenges faced by the mining sector in terms of Industry 4.0.

The key obstacles, as illustrated on Fig. 2, are also found in the mining industry and can sometimes pose a major threat.

One example of such threat is the cost of compliance with the standards to ensure interoperability. The cost of compliance with new technologies is very high, but in the case of mining, it is additionally increased by the fact that the investment process in this industry is time-consuming and expensive. Adding to that, the mining industry also has to contend with the uncertainty of the ROI which is inherent in mine investments. This of course arises from the specific nature of the sector and the geological and mining conditions which significantly increase the investment risk.

Also, the time required to adapt the mining sector to the Industry 4.0 ideas will take longer the lengthy investment time in the sector will naturally prolong the implementation of new solutions.

The lack of qualified staff is another general obstacle which becomes particularly problematic for the mining industry. The sector has been struggling with generation gap for many years. There is a shortage of even the basic working staff and if we assume that Industry 4.0 will require employees well versed in new technologies, the gap widens.

Another issue faced by the mining industry may be the technical aspect of data - today, a number of various data recording systems are employed, not necessarily compatible to each other. It might also be necessary to develop new, local IT solutions to support the processes in small, selected parts of the technological process (Kęsek, 2017). This might make analysis of those processes difficult and analysis is one of the foundations of Industry 4.0.

The idea of an e-mine is the first concept conforming to the Industry 4.0 principles which has been applied for a number of years and whose premises comply with all relevant guidelines. The main purpose of the e-mine project is to improve both technical and economic efficiency. It also aims to improve the safety of the work environment, in particular by reducing physical work in favor of headwork, which highlights the need for appropriate know-how and competences of employees.

\section{PROCESS TRANSFORMATION AREAS IN THE MINING INDUSTRY}

The transformation of mining businesses into Industry 4.0 cannot focus on one aspect only. Four main areas can be distinguished which should undergo transformation. They are illustrated on Fig. 3.

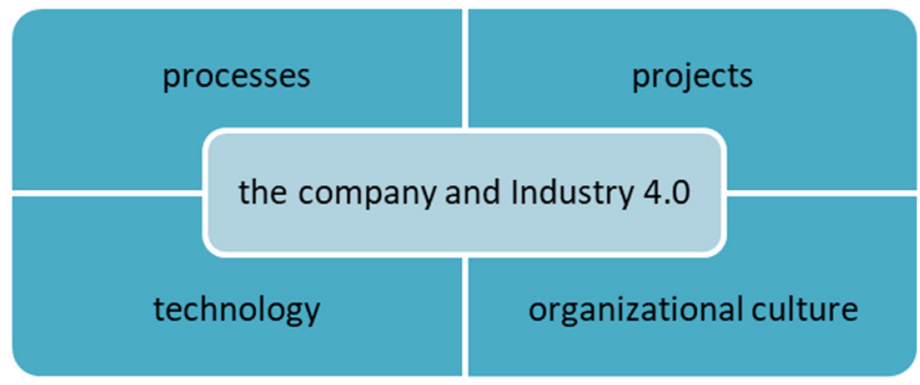

Fig. 3. Industry 4.0 transformation areas of a company

The technology area is clearly divided into two subgroups. The first subgroup is closely related to the technology of production processes applied in the companies. In the case of mining companies, the machinery park (and particularly the generation of the machines) plays an important role. 
The second group includes the information and communication technologies (ICT) which, if implemented and continuously developed in the companies, and combined with the availability of uninterrupted production data analysis, will provide the company with vast opportunities.

Therefore, the mining companies face the challenge of meeting the requirements of technology and computerization. Compliance with those requirements is crucial, even for the purposes of efficient management. The mutual relations and the need for development in this scope are clearly visible on Fig. 4.

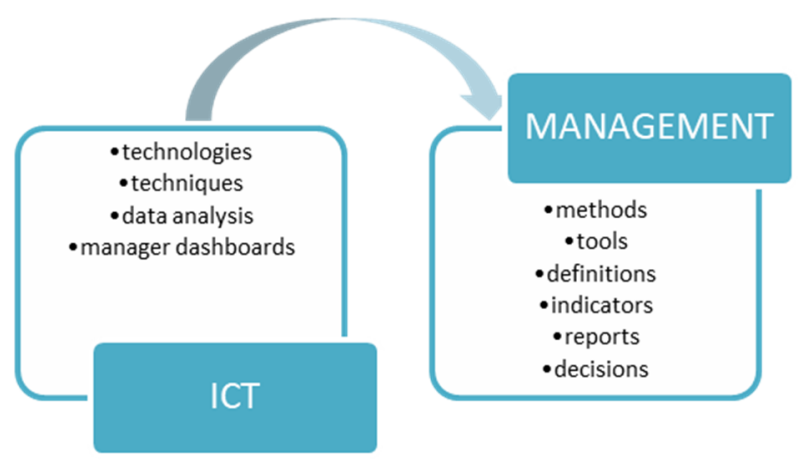

Fig. 4. Mutual relations of management functions and ICT

The outcome of the merging of ICT and management processes will lead to a potential improvement of process performance, as well as a reduction of costs, both operational and investment.

The organizational culture is a peculiar area in terms of Industry 4.0. By definition, ICT should provide the environment in which the organizational culture quality of the businesses could improve. All methods, technologies and processes related to Industry 4.0 will impact the organizational culture of a company (Fig. 5).

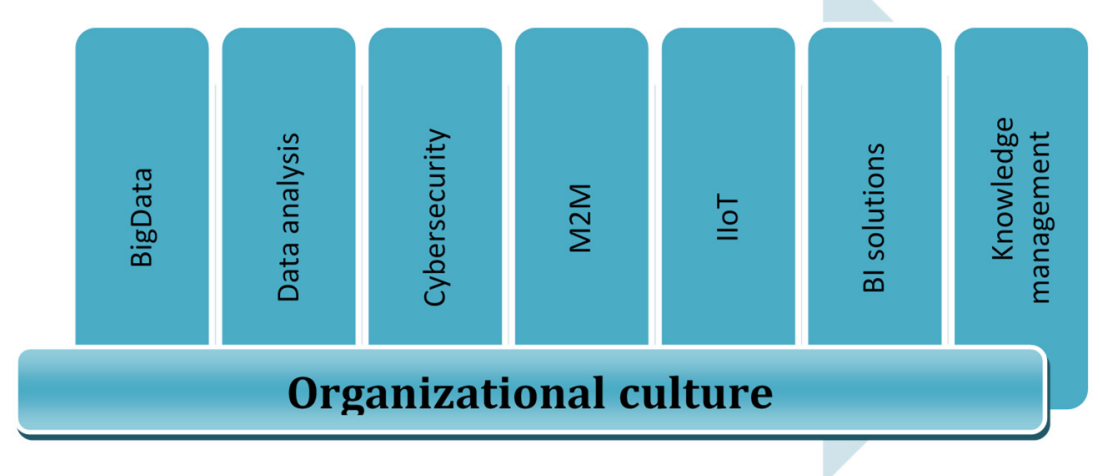

Fig. 5 The impact of Industry 4.0 solutions on the organizational culture

The change of the organizational culture of businesses will thus be enforced by the transformation of the businesses themselves. As evident from the studies on the issue (Report: Przemysł 4.0), the lack of digital culture and training is the most difficult challenge for half of the surveyed companies who are interested in the Industry 4.0 concept. In the same survey, $69 \%$ respondents said that increasing internal competences related to data analytics was crucial, and $50 \%$ reported the lack of appropriate culture and training in their organizations. It is clear then that the culture of the organization is the area that must be focused on in terms of Industry 4.0, since such "cooperation" can be most beneficial for the company (Fig. 6). 


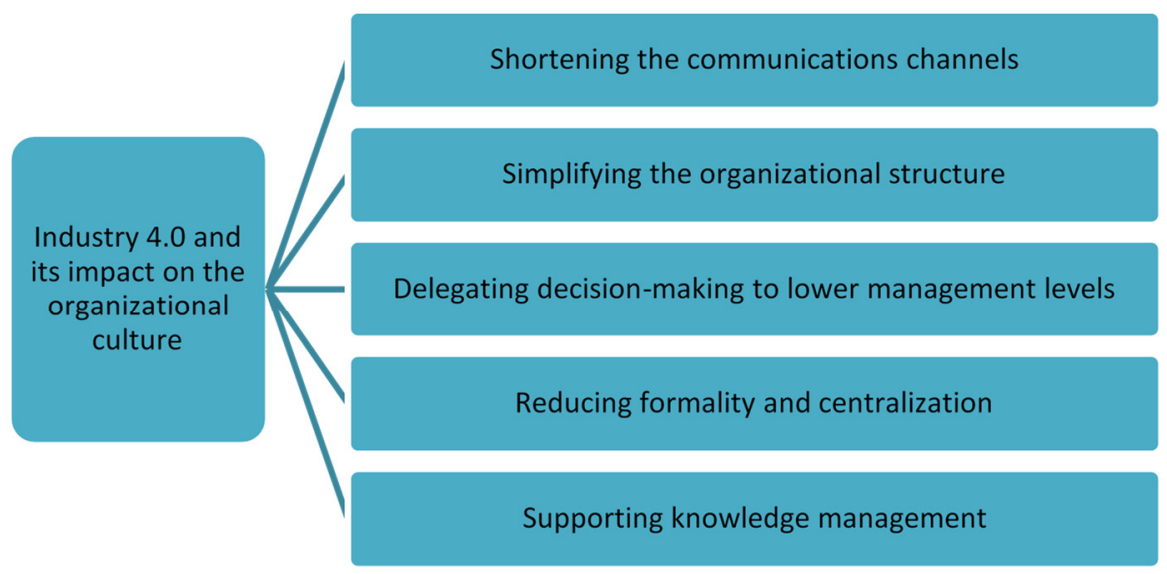

Fig. 6. The benefits of Industry $\mathbf{4 . 0}$ for the shape and level of organizational culture Source: own work on the basis of (Crowston, 2000; Tworek et al., 2015).

\section{CONCLUSION}

Transformation of mining businesses into Industry 4.0 appears unavoidable. Due to the specific nature of the sector, the transformation will not be an easy one. According to the premises of Industry 4.0, transformation should take place on multiple planes at the same time. Given the fact that the organizational culture of businesses is one such plane, it becomes clear that the people of the company, working with the new technologies and redefined processes, can become the driving force of change of Industry 4.0. We should bear in mind that it is a concept where humans, machines and processes are interconnected. Therefore, the obstacles and barriers in the mining industry discussed herein should be systematically eliminated and overcome by businesses in order to succeed in the Industry 4.0 environment.

\section{ACKNOWLEDGEMENTS}

This paper was supported by AGH University of Science and Technology [no. 11.11.100.693].

\section{REFERENCES}

Bąk P., Sukiennik M., Kowal B.(2016), Kultura korporacyjna w aspekcie procesów zarządczych w polskich przedsiębiorstwach wydobywczych, Inżynieria Mineralna Journal of the Polish Mineral Engineering Society, 17(2), pp. 135-144.

Crowston K. (2000) Processes as theory in information systems research. Arlborg, Germany, International Working Conference on the Social and Organizational Perspective on Research and Practice in Information Technology,.

Kęsek M., (2017) Visual Basic as a Tool for Monitoring and Analyzing Machines, Inzynieria MineralnaJournal Of The Polish Mineral Engineering Society, 18 (2), pp. 195-200.

Li X., Li D., Wan J., Vasilakos A. V.,Lai C.F., Wang S., (2017)A review of industrial wireless networks in the context of industry 4.0, Wireless Networks .vol. 23, no. 1, pp. 23-41

Pomykalski A. (2001) , Zarządzanie innowacjami, PWN, Łódź p. 35

Qinglin Qi, Fei Tao, (2018), Digital Twin and Big Data Towards Smart Manufacturing and Industry 4.0: 360 Degree Comparison, Access IEEE, vol. 6, pp. 3585-3593,

Tworek K., Walecka-Jankowska K., Martan J. (2015) Structure reorganization due to IT information functions support for knowledge management., China-WSA Business Review, 14 (4): doi:10.17265/1537-1514/2015.04.005

Wan, D. Zhang, S. Zhao, L. T. Yang, and J. Lloret, (2014), Context-aware vehicular cyber-physical systems with cloud support: Architecture, challenges, and solutions, IEEE Commun. Mag., vol. 52, no. 8, pp. 106-113,

https://automatykab2b.pl/tematmiesiaca/10530-przemysl-40\%5d [Accessed 10 May 2018]

Report: Control Engineering Polska and Inżynieria\&UtrzymanieRuchu, (2017). [online] http://przemysl40.eu/2017/12/22/przemysl-4-0-z-perspektywy-polskiego-rynku/[Accessed 8 May 2018].

Report: Przemysł 4,0. [online] https://www.pwc.pl/pl/pdf/przemysl-4-0-raport.pdf/ [Accessed 2 May 2018]. 